\title{
PUSAT ESPORT JAKARTA
}

\author{
Kissi Apriani ${ }^{1)}$, Doddy Yuono ${ }^{21}$ \\ 1) Program Studi S1 Arsitektur, Fakultas Teknik, Universitas Tarumanagara, kissi.apriani.ce@gmail.com \\ 2) Program Studi S1 Arsitektur, Fakultas Teknik, Universitas Tarumanagara, Doddyy@ft.untar.ac.id
}

\begin{abstract}
Abstrak
Industri dalam pariwisata menjadi industri yang mengembangkan kota baik dalam ranah sosial ekonomi dan budaya. Industri pariwisata yang baik ialah industri yang dapat menghadirkan cross-branding tidak hanya lokal namun hingga internasional. Dalam konteks Metropolis, Kategori Sport tourism diharapkan dapat menjadi pilihan pariwisata yang baru dengan kombinasi beberapa program dan fungsi (Mix-Use). Besarnya antusias turnamen ESport dalam Asian Games 2018 yang diadakan di Indonesia menjadi lahan referensi utama dalam kategori pengunjung dan pemilihan karakter lokasi, sedangkan pada event Indonesia Gaming Experience 2018 menjadi refensi penulis untuk kombinasi program dan aktivitas dalam ranah E-Sport. Potensi E-Sport tidak hanya sebatas dalam ranah permainan elektronik, namun berkembang hingga kategori edukasi, profesi, serta rekreasi yang akan menjadi dasar program utama proyek ini. Maka dari itu, penulis memilih 3 program utama dalam Proyek "Pusat E-Sport Jakarta (Jakarta E-Sport Center)" yakni, E-Sport Turnamen Center, Training Center, dan VR X arcade base Game Center. Dengan adanya E-Sport Center di indonesia khususnya jakarta, proyek ini diharapkan dapat memberi ruang baru bagi masyarakat untuk mengenal dan menjadi tempat berkembang bagi generasi muda dalam menggali talenta dan pengetahuan.
\end{abstract}

Kata kunci: Arsitektur Metropolis, Arsitektur Pariwisata, E-Sport, Olahraga Pariwisata, Pusat E-sport.

\begin{abstract}
Tourism Industry is a main urban development sector that grows in social, economic, and culture. Good tourism Industry can get a cross-branding between country. Sports Tourism is expected to be a new choice for tourism that attracts young generation based on the enthusiastic in E-Sport exhibition category in Asian Games 2018 that hold in Indonesia. E-sport potential is not only into gameplay dan tournament, but also how to entertain visitor based on education, profession, and recreation that become the basis of this project main programs. Therefore, the author chooses 3 main programs in this project "Jakarta E-Sprot Center", specifically: E-Sport Tournament Center, Training Center, and VR X Arcade base game center. With these Jakarta E-Sport Center program, hopefully, can provide a new space for communities to grow especially for a young generation to explore their talent and knowledge.
\end{abstract}

Keywords: Architecture Metropolis, Architourism, E-Sport, E-Sport Center, Sports Tourism.

\section{PENDAHULUAN}

Industri Pariwisata merupakan salah satu cara dalam mengembangkan suatu kota/wilayah secara cepat. Dengan pariwisata, negara memiliki kesempatan untuk memperkenalkan identitasnya pada dunia (Cross-Branding) dan turut ambil andil dalam event internasional.

Jakarta sebagai ibu kota Indonesia menjadi salah satu gerbang utama pariwisata dengan persentase sebesar 30\% setelah Bali $40 \%$ dan $20 \%$ Kepulauan Seribu (E-News, pikiranrakyat.com,2017). Salah satu Sport Tourism yang berkembang pesat 5 dalam tahun ini, ialah Electronic Sports (E-Sports), hal ini dibuktikan dengan besarnya pasar E-Sports dunia yang berdampak hingga Indonesia. Definisi E-Sports menurut Britishesport.org adalah kompetisi video gaming, dimana orang bermain melawan satu sama lain secara online dan/atau dihadapan penonton di suatu arena tertentu dengan hadiah yang besar Indonesia menyikapi perkembangan E-Sports dengan mengakui secara resmi organisasi E-Sports nasional di tahun 2014 dan mengukuhkan Indonesia E-Sports Association (IeSPA) dibawah naungan Federasi 
Olahraga Rekreasi Masyarakat Indonesia (FORMI). Dalam Regional Asia Tenggara, Angka peningkatan E-Sports mencapai $+36.1 \%$ ( \pm 9.5 jt orang) lebih dari tahun 2016 dan Indonesia menduduki angka kedua terbesar dengan jumlah $3.1 \%$ ( \pm 2 Juta orang).

\section{METODE}

Metodologi Penulisan proyek ini, antara lain: Melalui pendekatan telaah literatur yakni, literatur primer dan literatur sekunder. Literatur primer berupa jurnal penelitian dan komplikasi data (Newszoo - E-Sport international research) serta literatur sekunder berupa buku (Architectural Tourism - Building for Urban Travel Destinations). Kajian terhadap permasalahan dicermati dengan pendekatan deskriptif (E-Sport sebagai kategori Sport Tourism Indonesia dengan perkembangan terpesat), Analisis (mengkaji data dan perkembangan E-Sport secara kuantitatif - data, table, dan grafik) dan sintesis (Menentukan proyek untuk mendukung perkembangan E-Sport berupa area turnamen dan training center).

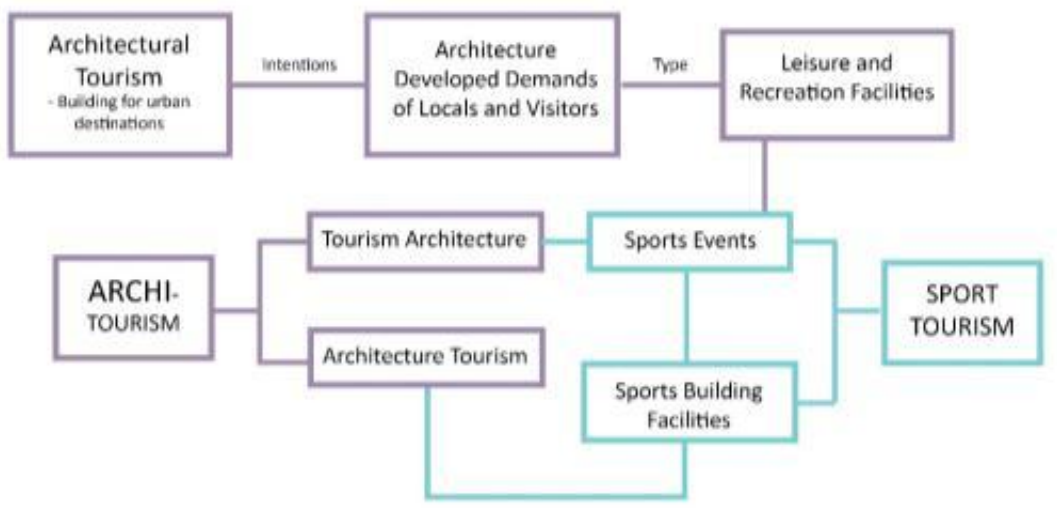

Gambar 1. Kerangka Berpikir Literature

Sumber: Architourism Tourism (Building for Urban Travel Destination + Bilbao Effect

Pada bagian Metode, penulis perlu menjabarkan data yang akan dikumpulkan selama proses penelitian/ desain dan selanjutnya secara rinci dan runut menjelaskan metode pengumpulan data, tahapan penelitian/ desain, metode analisis dan sintesis data hingga menghasilkan pernyataan kesimpulan. Jika penulis menggunakan alat penelitian atau simulasi desain yang spesifik, maka perlu dicantumkan juga dalam bagian ini. Apabila metode yang digunakan berasal dari beberapa sumber, maka penulis perlu menjelaskan kajian terkait metode tersebut secara jelas dengan menyertakan sumber asli. Penulis diharapkan memaparkan secara detail alasan dalam menggunakan suatu metode tertentu.

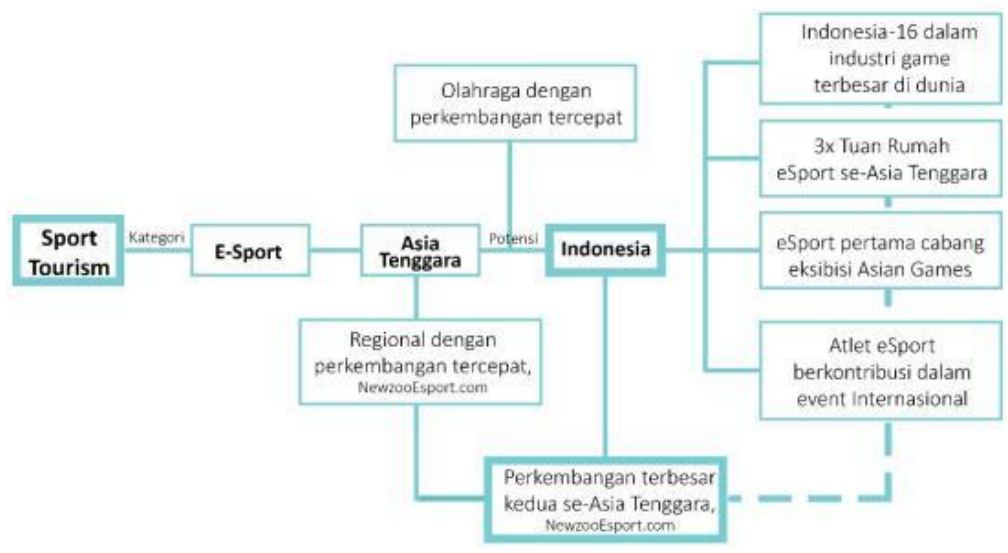

Gambar 2. Kerangka Berpikir Analisa Sports Tourism 


\section{DISKUSI DAN HASIL}

\section{Analisis Aktifitas/ Program}

Program dalam proyek ini terbagi menjadi 2 event yaitu Eventual dan Routine. Untuk yang eventual dibagi menjadi 3 program yaitu: arena stadium, eksibisi, dan area interaksi. Sedangkan routine dibagi menjadi E-Sports Education mnelalui Training Center, Game Center, dan Virtual Reality Center.

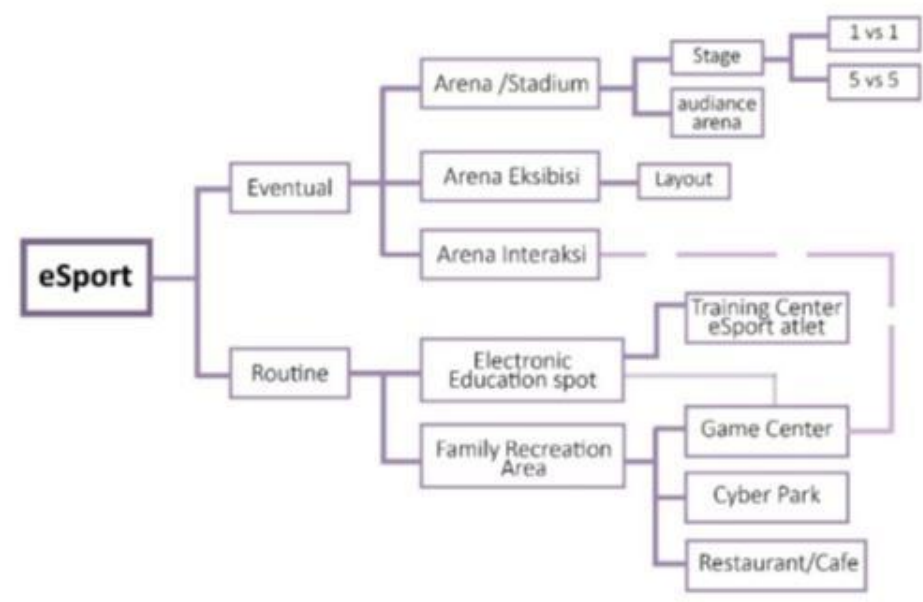

Gambar 3. Kerangka Berpikir Program E-Sport

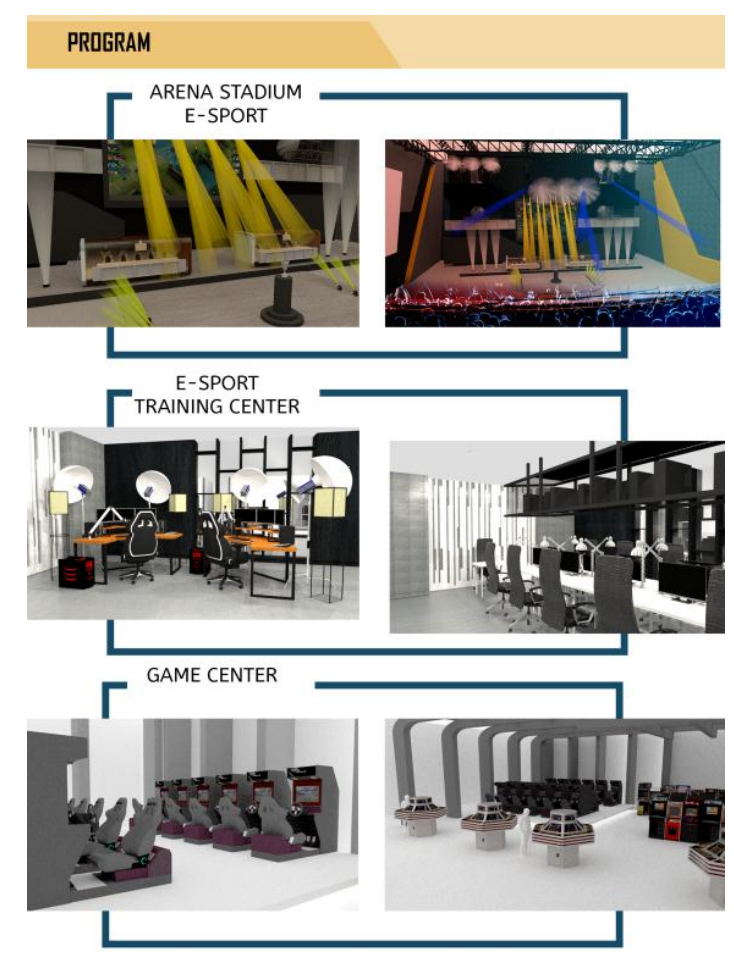

Gambar 4. Interior Program E-Sport Center

\section{Analisis Jumlah Pengunjung}

Mengacu pada studi presedent salah satu Event Yearly Game Indonesia atau yang dikenal dengan Indonesia Gaming Experience 2018, mengalami kenaikan pengunjung hingga \pm 20.000 orang (kurun waktu acara 3 hari). Hal ini dipengaruhi oleh variatif tournament E-Sport yang di tandingkan dan program pendukung seperti game center, card arcade, game developer eksibition, serta pertukaran kebudayaan jepang dan indonesia berupa cosplay baik kategori 
anime serta kategori hero indonesia yang telah digunakan untuk karakter game seperti game mobile legends.

Data yang diperoleh dari setiap event pengunjung mencapai $12.000-20.000$ pengunjung dengan kondisi khusus yakni:

1. Event berlangsung secara 2-3 hari dengan adanya program eksibisi game/perangkat game, serta pengembang game Indonesia yang memperkenalkan game lokal yang telah diminati hingga skala internasional.

2. Adanya beberapa turnamen yang berlangsung secara bersamaan namun memiliki kategori yang berbeda, contohnya pada Event Indonesia Gaming Experience 2018 memiliki 3 stage untuk turnamen 5 vs 5 , dan 2 stage kecil untuk turnamen 1-2 vs 1-2.

3. Adanya area untuk keluarga dan anak anak yang memainkan permainan sesuai umur, yakni board game dan arcade game.

Tabel 1. Studi Preseden Jumlah Pengunjung Event Esport

\begin{tabular}{|c|c|c|c|c|}
\hline EVENT & LOKASI & PENGUNUUNG & LIVE STRE.AMING & SKALA \\
\hline $\begin{array}{l}\text { RDDONESIA GANE CENTER } \\
2017\end{array}$ & $\begin{array}{l}\text { JAKARTA, } \\
\text { DNDONESLA }\end{array}$ & $13.600 \mathrm{crang}$ & 246.000 & Navionat \\
\hline BEKRUF Game Prime 2017 & $\begin{array}{l}\text { IAKARTA, } \\
\text { INDONESLA }\end{array}$ & $\begin{array}{l}647 \text { (traizing) - } \\
12.427 \text { (perigenjany) }\end{array}$ & - & Asia tenersea \\
\hline TOS 2017 & CHIBA, IEPANG & 270.080 enting & - & latrasazicas! \\
\hline $\begin{array}{l}\text { INDONESIA E-SPORT } \\
\text { CHAMPIONSHIP (201s) }\end{array}$ & $\begin{array}{l}\text { IARARTA, } \\
\text { INDONESLA }\end{array}$ & 20.600 - Peserta & - & laterasuicna! \\
\hline BATTLE OF VALOR & $\begin{array}{l}\text { IAKARTA,INDONES } \\
\text { IA }\end{array}$ & 5000 orasg & - & ledseesia $\rightarrow$ imernasiosel \\
\hline
\end{tabular}

\section{Analisis Element Dalam Turnamen Esport}

Kebutuhan element/alat atlit E-Sport yang mendukung arena turnamen berdasarkan genre game meliputi:

\section{Multiplayer Online Battle Arena (MOBA):}

- Layout pengguna Stage: 5 atlit +1 Coach +1 Stage Control

- Perlengkapan: Smartphone, Headphone, Camera Standing, dan Camera Cam.

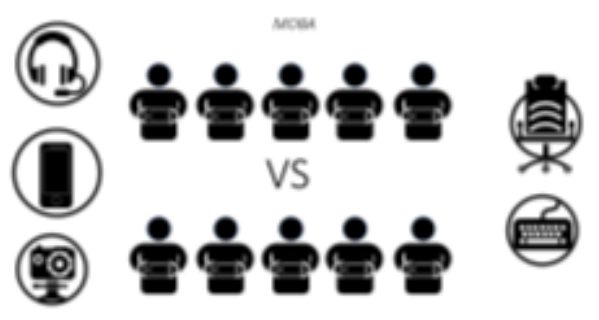

Gambar 5. Layout dan Perlengkapan

2. Multiplayer Online Battle Arena (MOBA) + Real Time Strategy (RTS) :

- Layout pengguna Stage: 1 atlit + 1 Stage Control

- Perlengkapan: Smartphone, Headphone, Camera Standing, dan Camera Cam.

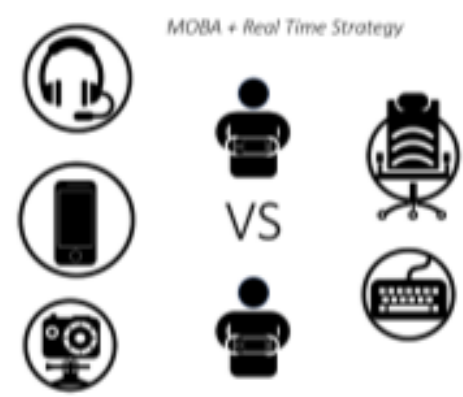

Gambar 6. Layout dan MOBA + RTS 


\section{Sport Games and Fighting Games:}

- Layout pengguna Stage: 1-2 atlit + 1 coach + 1 Stage Control

- Perlengkapan : PC/Monitor, Headphone, Controler (spesial game fighting), Console, Camera Standing, Camera Cam.

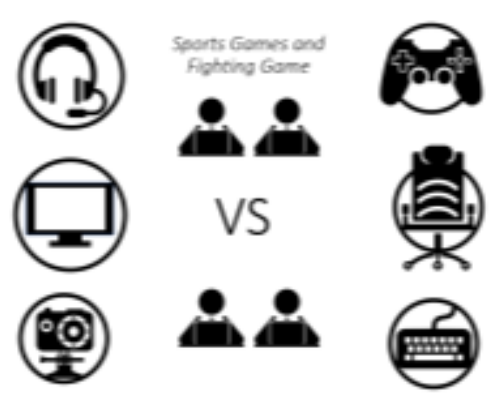

\section{Analisis Tapak}

Gambar 7. Layout dan Fighting Games

Karakteristik kawasan dan tapak yang dipilih ialah kawasan Puri Indah, Jakarta Barat. Hal ini dikarenakan Puri Indah menjadi kawasan yang menjadi pusat kegiatan penyediaan Kawasan Sentra Primer Barat dan menjadi pusat terwujudnya kegiatan tersier di kawasan kantor walikota jakarta barat (Perda DKI No.1 Tahun 2014 - Tentang RDTR).

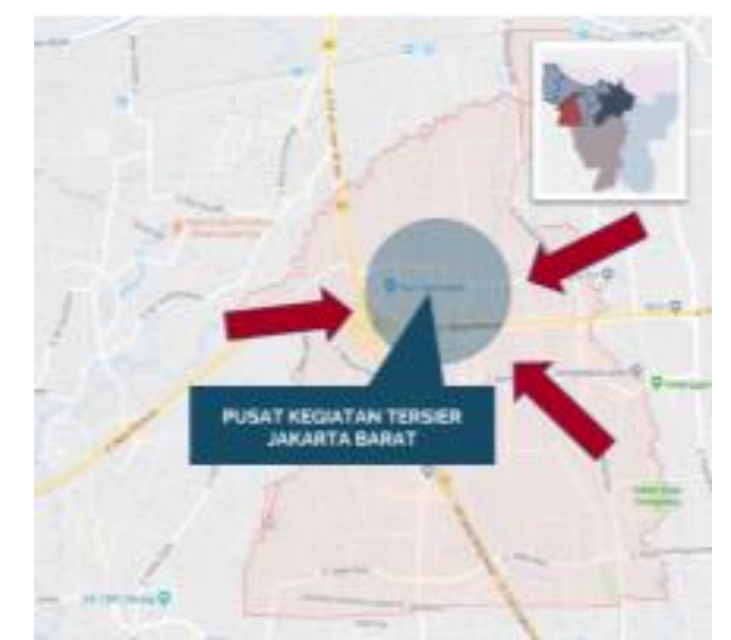

Gambar 8. Kecamatan Kembangan, Jakarta barat

Tapak berada pada sisi timur kantor walikota jakarta barat yakni di jalan Puri Permai Blok W No.82, RT.2/RW.2, Kembangan Sel., Kembangan, Jakarta Barat. 


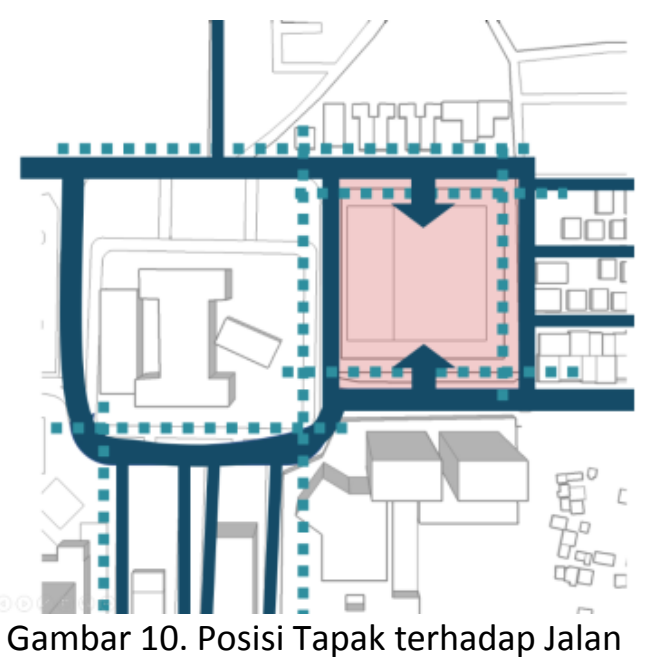

Tapak dikelilingi oleh jalan arteri sekunder yang menjadikan tapak ini mudah diakses oleh kendaraan. Disisi selatan tapak berbatasan dengan Lippo mall Puri, yang menjadi target utama pengunjung dikarenakan adanya akses dan fasilitas shuttle bus Lippo Mall yang berada tepat disisi selatan tapak yakni diberbatasan antara tapak dan Lippo.

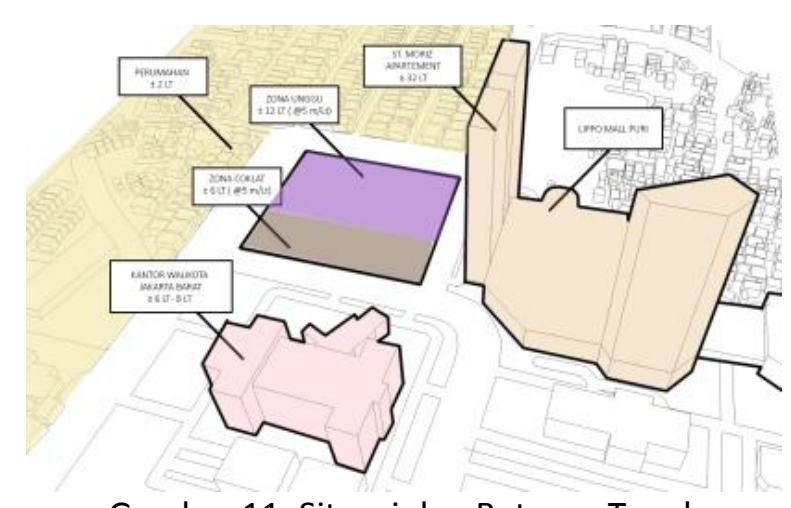

Gambar 11. Situasi dan Batasan Tapak

Selain akses kendaraan, akses yang diutamakan ialah kenyamanan pedistrian dan keterbukaan antara massa dan ruang hijau. Maka penentuan poin poin dalam ruang terbuka ditentukan dari arah datang dan sirkulasi pengunjung.

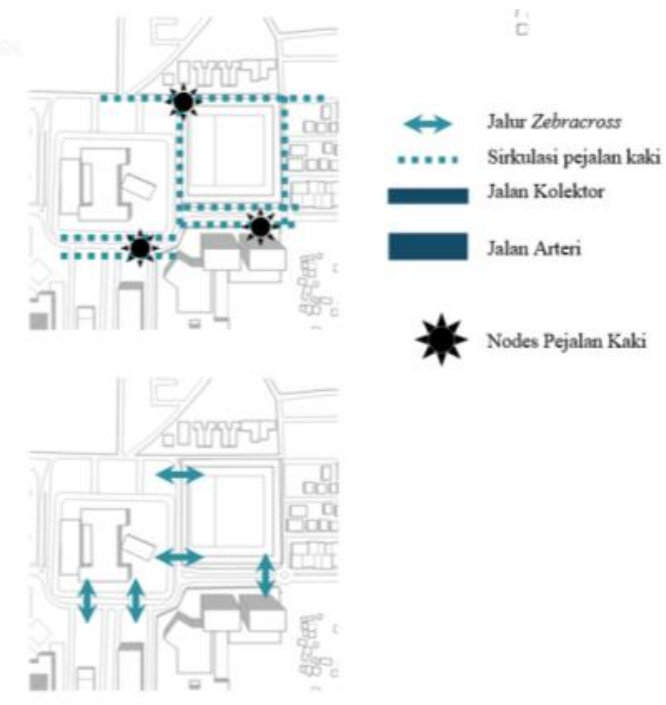

Gambar 12. Diagram point dan sirkulasi pejalan kaki 


\section{Analisis Konsep E-Sport}

E-Sport berkaitan erat dengan pergerakan Futuristik yang memiliki karakter khusus, yakni, maksimalitas fleksibilitas (dalam angle dan bentuk gubahan) dan pencahayaan, serta pengunaan elemen kaca dan baja sebagai façade bangunan (Londonhua, 2017).

1. Motion and Shape, yaitu membangun zoning dan ruang berdasarkan sirkulasi dan hubungan ruang yang berkaitan. Dengan mengkoneksikan program utama dan pendukung, ruang ruang yang terbentuk menjadi lebih efektif dan fleksible dengan mengutamakan moving partition yang disesuaikan dengan event yang berlangsung.

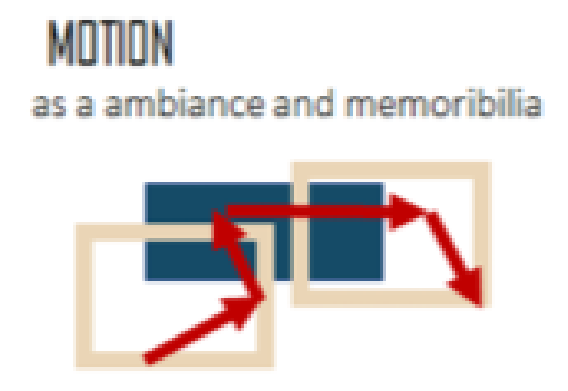

Gambar 13. Motion Diagram

2. Light, yaitu pengunaan warna neon yang menjadi ciri khas E-Sport yang dikombinasikan menjadi façade utama dan interior bangunan.

3. Teknologi, selain Cyber Park, penggunaan Screen dan Device yang mendukung Façade bangunan, dan menjadi bagian dalam pengalaman ruang untuk pengunjung dan bersifat fleksible berdasarkan event.

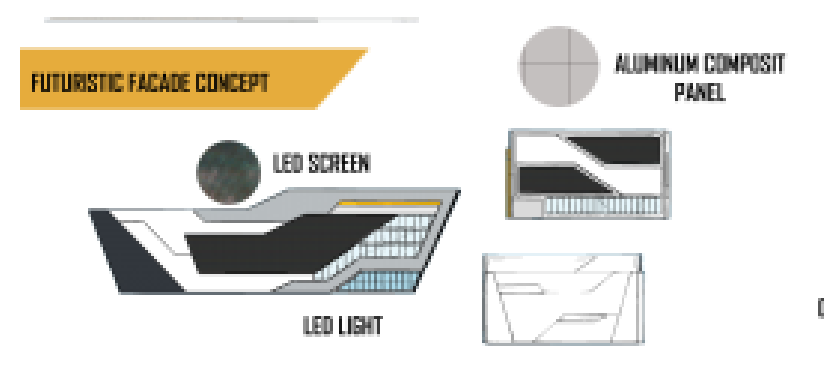

Gambar 14. Façade E-Sport Center

4. Smart Parking Concept - konsep Smart Parking yang diadaptasi ialah konsep Vertikal Transfer Device System (Takashimaya Construction \& Development,2011).

Dengan mengadopsi konsep ini, jumlah parkir dapat meningkat hampir dua kali lipat jika dibandingkan dengan parkir konvensional sebanyak \pm 350 parkir mobil.

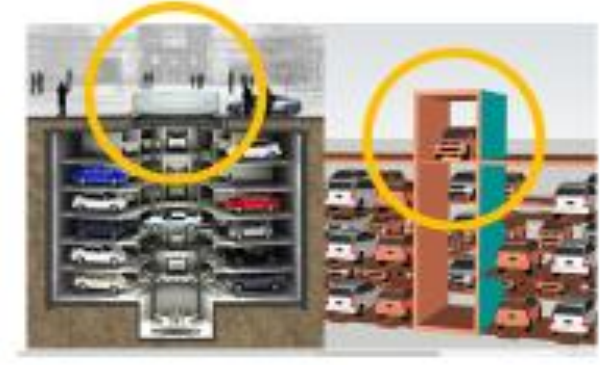

Gambar 15. Smart Parking System 
5. Cyber Park Concept - Sebagai penerima pengunjung pertama Cyber Park dilengkapi dengan Connecting Tree yang memiliki device untuk mengakomodir pengunjung untuk bermain satu dengan yang lain. Permainan dapat beragam dan bertujuan untuk mendekatkan pengunjung satu dengan yang lain sehingga dapat bersosialisasi, tempat meeting point klub, dan tempat refreshing bagi pengunjung.

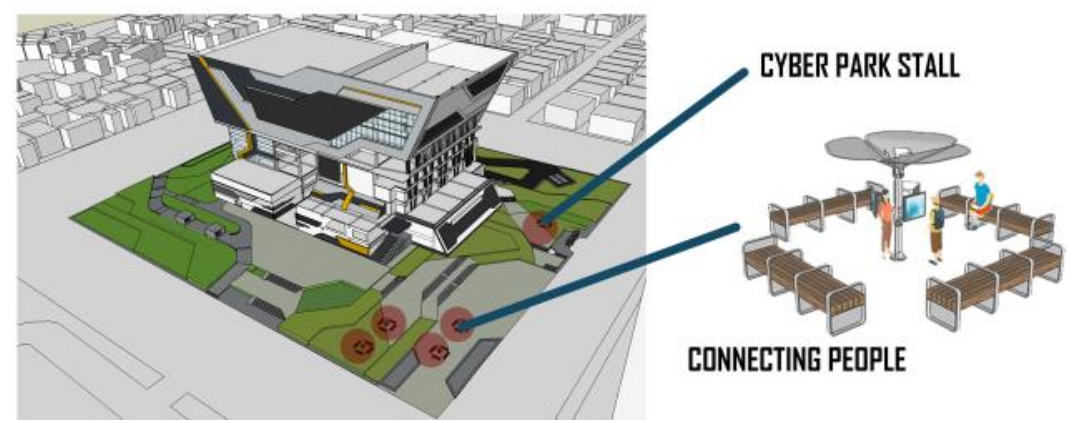

Gambar 16. Cyber Park

\section{Proses Perancangan Dalam Tapak}

1 AKSESIBILITAS

Aksesibilitas kendaraan berada di sisi timur tapak dengan pertimbangan intensitas lalu lintas yang tidak bersinggungan dengan jalan dan fasilitas sekitar tapak. Sedangkan untuk pejalan kaki diutamakan pada sisi barat, barat daya, dan selatan sisi tapak. Hal ini dimaksudkan untuk memudahkan pejalan kaki dalam mengakses halte kendaraan serta fasilitas sosial lainnya.

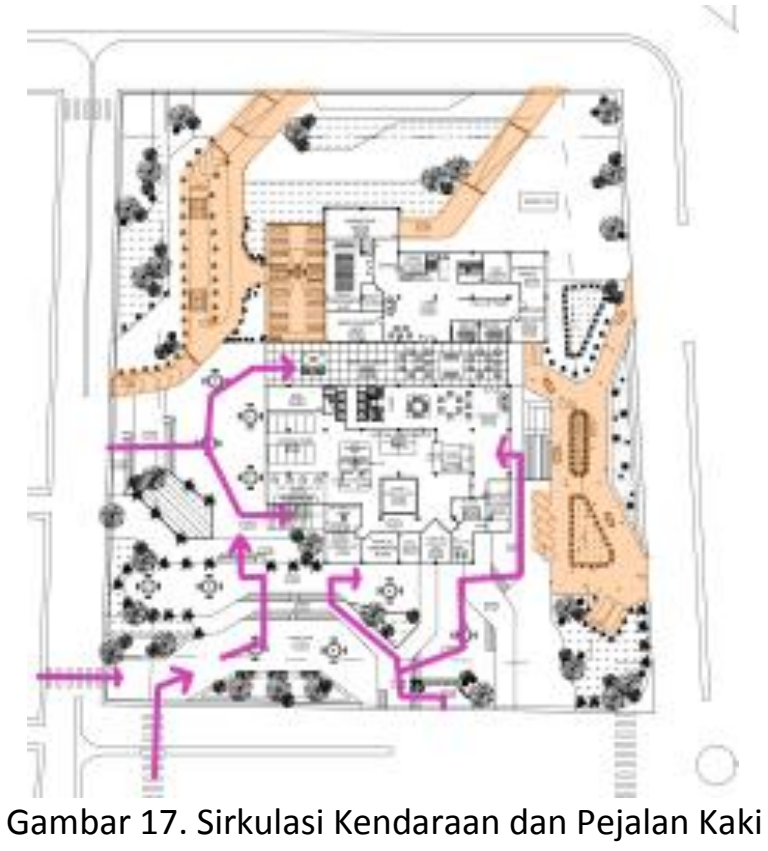

\section{PROSES GUBAHAN MASSA}

Gubahan massa bertemakan Scifi Futurism yang memiliki konsep mewujudkan suatu imajinatif futuristic yang dikembangkan menjadi tampak bangunan serta bentuk yang menyerupai markas teknologi. Bentuk sisi barat bangunan tidak memiliki sudut yang meruncing mengingat kantor walikota memiliki sifat yang formal, namun sebaliknya, pada sisi selatan dan utara tampak dibuat meruncing sesuai dengan konsep futurism. 

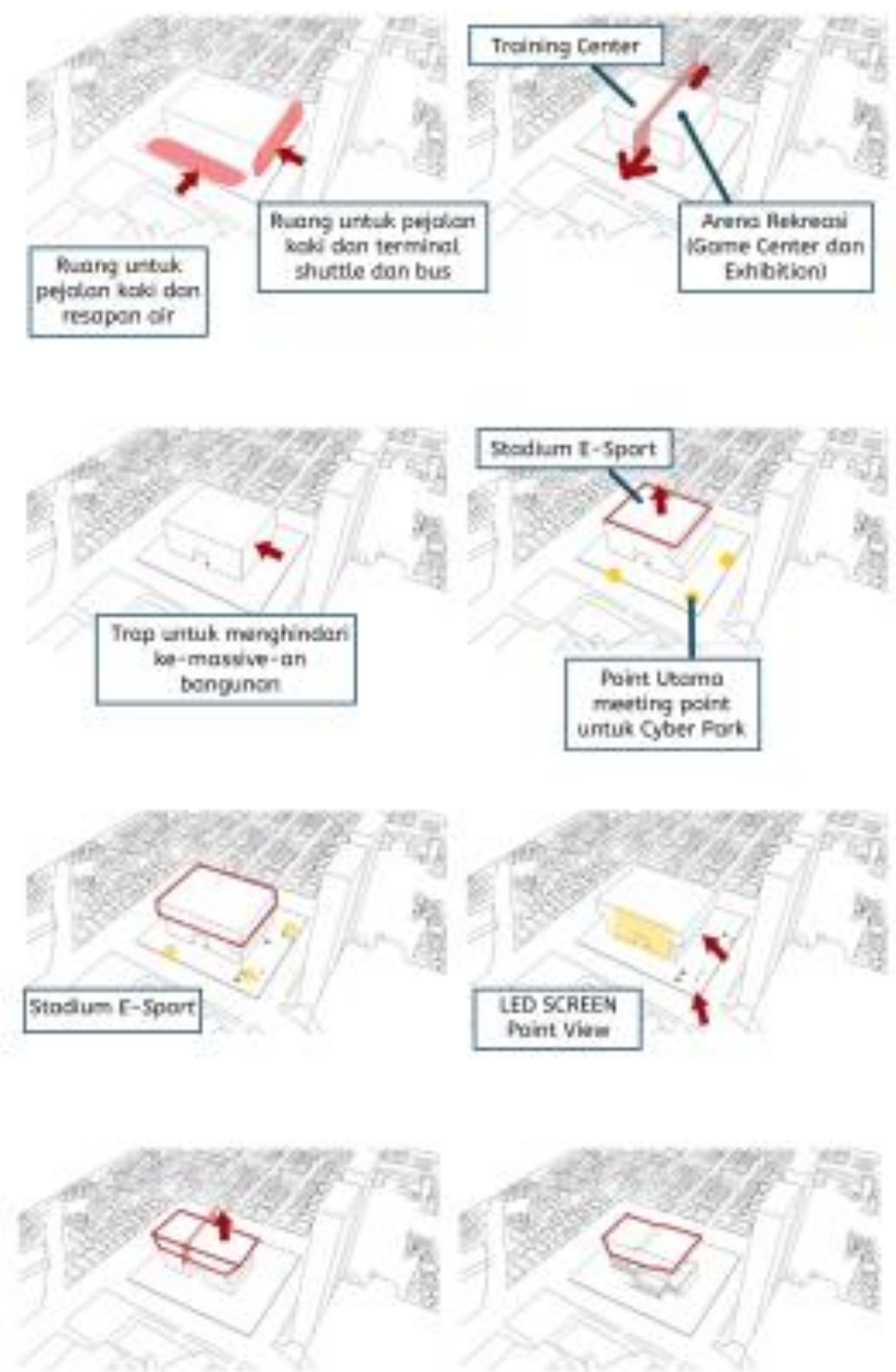

Gambar 18. Proses Gubahan Massa

\section{KESIMPULAN DAN SARAN}

Jakarta E-Sport Center, menghadirkan program rekreasi serta edukasi yang bertujuan untuk mengembangkan talenta dan pengetahuan akan teknologi kepada masyarakat khususnya generasi muda. Dengan hadirnya E-Sport Center diharapkan dapat menjawab permasalahan khususnya komunitas - komunitas muda game dalam memberi venue dan area untuk menyelenggarakan turnamen, gathering, maupun edukasi positif untuk masyarakat.

\section{UCAPAN TERIMA KASIH}

Terima kasih kepada atlet E-Sport Indonesia yang telah menyumbangkan prestasi dan mengembangkan minat E-Sport di Indonesia, Terimakasih untuk developer game indonesia dan penyelenggaraan Event E-Sport indonesia yang telah membantu anak muda dalam berkarya dan bekerja hingga menghadirkan bermacam profesi baru yang dapat menyerap tenaga kerja dan dapat menjadi industri baru pada sektor pariwisata. 


\section{REFERENSI}

Asiangames,2018. Cabang olahraga Asian Games. https://asiangames2018.id/merchandise?utm_source=asiangames2018\&utm_medium=n avigation_link_desktop\&utm_campaign=ag_official_merchandise. Dikunjungi 10 Juli 2018.

Cooke, sam. Newzoo says Southeast Asia is esports fastest growing market.https://esportsinsider.com/2016/12/southeast-asia-esports-fastest-growingmarket-says-newzoo/. dikunjungi pada 8 July 2018.

Data virtual Media. https://esports insider.com/2016/12/southeast-asia-esports-fastestgrowing-market-says-newzoo/.

Funk, Daniel C. dan Pizzo, Anthony D., 2018. Embracing E-Sport education and research opportunities. https://www.sciencedirect.com/science/article/pii/S1441352317300670; dikunjungi pada 11 Juli 2018.

Jesse Schell's Tetrad (Aesthetics, Narrative, Mechanics, Technology) from the Art of Game Design (2008);

Kiley, Oliver. 2015. BIG GAME THEORY, A GENOMIC FRAMEWORK FOR GAME ANALYSIS. research and analysis.http://www.big-game-theory.com/2015/08/a-genomic-frameworkfor-game-analysis.html.

Marrujo, Robert. 2017. E-SPORT PROJECT. https://binx.news/binx-news/oakland-esportsarena-a-game-changer-in-bay-area/.

Pertiwi, Wahyunanda Kusuma. 2017. Menakar Potensi eSport di Indonesia. Kompas.com, dikunjungi pada 11 agustus 2018.

Slickster. 2016. The History Of E-sports Infographic.http://www.slickstermagazine.com/historyof-esports-infographic/. dikunjungi 4 Sep 18.

Smigiel, Kacper. 2018. TEAM KINGUIN. https://teamkinguin.com/team-kinguin-performancecenter-en/;dikunjungi pada 11 juli 2018.

Superdata. 2018. Market Virtual Reality. https://www.superdataresearch.com/wpcontent/uploads/2016/08/SuperData-Virtual-Reality-Market-3.png.

Techopedia.2018. Techopedia explain

gamer. https://www.techopedia.com/definition/1912/gamer, diunduh 15 Agustus 2018.

Yu, Annie Z. VIDEO GAME VENUE. Texas.https://www.ocregister.com/2014/05/16/videogame-venue-to-soon-bring-players-under-one-roof/, diunduh 2 Juli 2018. 